\title{
Phenomenology as Critique of Institutions: Movements, Authentic Sociality and Nothingness
}

\author{
IAN ANGUS
}

This essay will seek to demonstrate that phenomenological philosophy entails a practice of social and political criticism. ${ }^{1}$ Phenomenological philosophy is understood, not as an affiliation to one or more well-regarded names, but as an orientation to philosophy that came into existence through the work of Edmund Husserl, was continued by Martin Heidegger, and has been developed in more recent times by other thinkers such as Jacques Derrida even though it can be traced through the history of philosophy before this formulation and, indeed, one may argue that this history is only comprehensible due to its phenomenological component. Through and behind these names, this understanding of phenomenological philosophy characterizes an orientation to the practice of inquiry based in experience that may require a critique of some aspects of the thought of these major practitioners.

The original demand of phenomenology is that theoretical and scientific judgments must be based upon the giving of the 'things themselves' in self-evident intuition. This demand could only emerge as such if the thinker was already gripped by a suspicion that many claims to knowledge, or adequate evidence, were not actually such. For this reason, phenomenology re-experiences and radicalizes the situation described by Descartes in the first part of Discourse on Method: there are many authorities that contradict each other, 
many different approaches and things to consider; the only course of action is to think everything through from the start for oneself.

The continuous radicalization of the demand for adequate evidence is what characterizes phenomenological philosophy and determines a practice of social and political criticism. The radicalization of evidence can be traced through four subsequent phases: 1. a critique of institutions through the method of unbuilding (Abbau, Destruktion, déconstruction); 2. presencing, or coming into presence, that directs one's attention to the social movements of one's time through which that which is pressed-out of the social form manifests itself; 3. authentic being-with (Mitsein) in which the sociality of human life is brought to the limit-condition of human life in being-toward-death; 4. nothingness, in which that which withdraws in any manifestation is incapable of a Hegelian re-immanentization as negation of the negation and thus points to an ethical dimension outside of history.

\section{The Transcendental Reduction as a Reflexive Paradox}

It is Husserl's discovery and practice of the transcendental reduction that inaugurates the specificity of phenomenological philosophy. The locus classicus of this inauguration is in Ideas 1, though this is neither its first nor last appearance. It is not too much to say that the meaning of the transcendental reduction becomes newly problematical at each moment of Husserl's thought - which is to say that for phenomenology reflexion on its own possibility is a constitutive feature of its philosophical vocation. In section 30 of Ideas 1, Husserl describes the natural surrounding world of physical things, animate beings, ideal objectivities (such as mathematics and other sciences), and intersubjective human relations in terms of a "general positing" characteristic of "the one spatiotemporal actuality" which is 
taken in this positing as "a factually existent actuality and also accept[ed] ... as it presents itself to me as factually existing" (56-7, emphasis removed). It is this natural world that he later called the "life-world." Its description is so ordinarily evident that it seems to raise no issues at all, except the sense in which it can be described as correlated to a "general positing which characterizes the natural attitude" by one human being or another or even all of them (57). It seems rather that the natural existence of the world is presupposed by all human orientation of any sort to such a degree that it is not the object of a positing at all but rather perhaps a necessary presupposition or even an assumption too deep and pervasive to be brought to conscious articulation. We may remark here that it seems that the description of the natural world as correlated to a "general positing" presupposes another standpoint, not that of the natural world, that is yet to be articulated. Similarly, the description of the natural world as correlative to an "attitude" should not obscure the fact that it is like no other attitude one normally experiences and raises the problem of the use of language drawn from the natural attitude to characterize experiences available only within the transcendental reduction adequately. In this sense, it is a reflexive paradox (see Angus, (Dis)figurations 3649, 61-2, 76-87).

Section 31 of Ideas 1 begins with a short sentence remarkable in its abruptness. Stating that "[i]nstead of remaining in this attitude, we propose to alter it radically" (57, emphasis removed). Husserl comments that the general positing characteristic of the natural world is not like other positings insofar as it is not a single act of positing but rather a pervasive and continuous belief operative through any presentation of anything at all. Nonetheless, precisely because it is ubiquitously operative through single acts of positing, "it is essentially possible to base on this characteristic an explicit (predicative) judgment of existence 
agreeing with it" (58). It is this explicit predicative judgment that is the "general positing which characterizes the natural attitude." Thus the transcendental reduction requires a prior activity of logos which transforms the pre-predicative so-called 'judgments' of the natural world into a predicative judgment capable of suspension. In this respect the reduction is indebted to Descartes for the "attempt to doubt universally" even though it cannot yield "a sphere of absolutely indubitable being" as he thought but nevertheless does demonstrate that an unrestricted doubt is within the realm of our "perfect freedom" (Ideas 58). It is this suspension of judgment with regard to the explicit positing that yields the transcendental reduction. As Husserl says, "[w]e put out of action the general positing which belongs to the essence of the natural attitude; we parenthesize everything which that positing encompasses with respect to being: thus the whole natural world which is continually 'there for us,' 'on hand,' and which will always remain there according to consciousness as an 'actuality' even if we choose to parenthesize it" (61).

It is the transcendental reduction that allows the 'retrospective' characterization (in a logical and not a temporal sense) of the natural world in terms of a "positing," and an "attitude," which can be brought to predicative judgment and suspended. Thus the results of the transcendental reduction are in a certain sense operative before they are enacted in the reduction themselves. This is evident in the prior activity of logos in predicatively forming the pre-predicatively experienced contents of the natural world. Such a reflexive paradox is constitutive of phenomenological philosophy and determines the sense in which reflexion on its own possibility is a constitutive feature of the philosophical vocation.

Husserl's apprehension of this vocation underwent considerable transformation and radicalization during his lifetime and, teleologically understood, determines the sense of this 
investigation. The relation between pre-predicative experience and its formation into predicative judgments was again a key issue when he claimed that the crisis of the sciences and the culture based on them due to their loss of meaning which "does not encroach upon the theoretical and practical successes of the special sciences; yet it shakes to the foundations the whole meaning of their truth," a truth which pertains to "the meaning of their original founding as branches of philosophy, a meaning which they continued to bear within themselves" (Crisis 12). Given that this crisis is not a perennial problem for philosophy but a uniquely modern problem (14), it depends upon the internal formation of the modern sciences (the scientific problem), the universal form in which they shape a culture (the problem of scientifico-technological culture), and the manner in which this modernity took over and transformed the philosophical and scientific heritage from which it was inaugurated (the problem of history). The crisis thus envelops both the sciences and the life-world.

\section{Unbuilding: Crisis and Critique of Institutions}

The life-world is constituted by a lived, embodied, intersubjective spatio-temporality whose explication is made possible by the transcendental reduction. Here phenomenology encounters the question of history, not simply as empirical history, but as transcendental history. In order to understand the constitution of modernity it is necessary to understand the original formation and perdurance of the structures that pre-form subsequent experiences. In The Crisis of European Sciences and Transcendental Phenomenology, Husserl places greatest emphasis on Galilean science, but also modern psychology and the ancient origin of geometry, and there is no reason to believe that these constitute an exhaustive set. It is in the 
context of clarifying the sense in which Galileo established the new science that Husserl introduces the term Urstiftung - which can be translated as 'primal establishment,' but I will translate mainly as 'institution,' and occasionally as 'inauguration' (73-4). The advantage of the term 'institution' is that it can be used in two senses, both of which are relevant to the concept here. Something is 'instituted' in the sense of being brought into being and something is an 'institution' in the sense of an organized structure within which intersubjective and material relations are organized. ${ }^{2}$ It is mainly a temporal structure in the sense in which it is different to be born after the introduction of compulsory public schooling than before it, but it contains a spatial dimension in the sense that such an introduction begins in some places before others whose 'uneven development' then exerts an interactive 'push and pull' between them. One can direct attention to the primal establishment or inauguration of an institution in order to point to its coming into being and therefore to the original temporality that it institutes. One can direct attention to its 'institutional' character in order to point to the continuing shaping that it exerts over subsequent experience. Urstiftung is thus a species of constitution specific to transcendental history. Transcendental history is thus concerned with the temporal inscription of the life-world such that subsequent empirical history takes a different form after than before its inauguration. ${ }^{3}$ The process of inauguration may be drawn out in empirical history but from the viewpoint of transcendental history it constitutes one historical event. During this event of institution, its full implications and consequences are not yet evident. Similarly, certain elements enter into the institution whose origin is simply passed over and whose validity is simply taken for granted due to its prior sedimentation in tradition. Thus, more is given in the instituting event than is visible at the time. An event in transcendental history will thus often take considerable empirical history 
for its institution to become a question worth investigation, let alone be completely clarified. Such was the case for the mathematization of nature by Galileo that Husserl began to investigate within transcendental history due to the problem that the contemporary crisis of the sciences posed for the relation of science and philosophy to human life in the natural world. Husserl was well aware of a circle here:

The historical reflections we embarked upon ... demanded clarity concerning the origin of the modern spirit and ... the origin of these sciences. That is to say: clarity concerning the original motivation and movement of thought which led to the conceiving of their idea of nature, and from there to the movement of its realization in the actual development of natural science itself (Crisis 57).

Such an intertwining between empirical and transcendental history does not abolish their difference (contra Landgrebe, Phenomenology 200) but, for Husserl, demands that the investigation "proceed back and forth in a zigzag pattern" from contemporary breakdown to original institution and back again (58).

The 'loss of meaning' of knowledge for human life that the crisis of the sciences makes evident requires an inquiry into the constitution of meaning in the institution of the sciences and its shaping of modern culture. This inquiry takes a particular form determined by its object and the historical event of crisis that Husserl called 'dismantling,' or 'unbuilding,' (Abbau) which is the origin of the terms 'Destruktion' and 'deconstruction' in Heidegger and Derrida (see Landgrebe, "Editor's Foreword" 5). ${ }^{4}$ It involves a going back from the pregiven world and its sedimentations of meaning to the "original life-world" and it further requires a going back from the original lifeworld to investigate the constitution of the lifeworld itself (Husserl, Experience 50). In other words, predicative judgments must be traced back to the forming of pre-predicative experience, which they accomplish and then this pre-predicative experience itself must be dismantled. This critical activity rests on the 
crisis of the European sciences, which is a contemporary event that itself institutes the inquiry itself. ${ }^{5}$ This event consists, most generally, in a dislocation between predicative and pre-predicative judgments or a crisis in the forming of lifeworld experience by formal knowledge-systems. It is this crisis that calls forth the explication of transcendental history as the phenomenological critique of historical institutions.

\section{Manifestation of the New as New}

Adequate evidence understood as the presence of the things themselves in intuition, when phenomenology encounters the problem of the formation of presence through sedimented meaning-structures, encounters history. Uncovering such meaning-structures requires a process of inquiry that brushes history backward toward its originary instauration. The focus of phenomenological description on the 'constitution' of meaning thereby encounters the 'institution' of meaning, which is a species of constitution defined through a temporality of before/after, in an event of coming-to-presence. The present-ness of adequate evidence has come to be through an event such that it functions as the taken-for-grantedness of an institution. In this way, a tradition is instituted, which means that what is taken to be adequate evidence within a tradition depends upon a prior event of presencing. The transcendental history that uncovers such meaning-structures thus becomes a critique of institutions and their sedimented, taken-for-granted meanings that have become 'ultimates.' It is a deconstruction of ultimates. This critique of institutions must be concretized in a contemporary focus on the destitution of institutions and the emergence of new institutions, which is signalled by contemporary social movements. 
Contemporary social movements such as environmentalism and feminism, as well as earlier movements such as the workers' movement, are significant in this context. Social movements manifest what is left out of prevailing institutions, develop a language for what is left out, and propose alternatives to prevailing institutions. Analytically, social movements are the index of the extent to which a hegemonic 'reigning presence' impedes a new encounter with the event of presencing. Experientially, social movements construct a new identity for a subjectivity that, in a paradoxical fashion, feels the insufficiency of its own identity under the reigning institution. (For an extended analysis of social movements in these terms, see Angus: Emergent Publics; Primal Scenes, Part III; for a condensed version, see "Media.")

The role of the phenomenological critic with respect to such movements is threefold: First, he or she must clarify the critique of institutions already underway in the movement and explore its implications for present political possibilities. Second, it must analyze such movements against the background of prevailing institutions and probe the limitations of such institutions. Third, it must clarify what may be called the 'infinite dimension' of such movements, the dimension of such movements that exceeds any possible practice but nevertheless reveals a dimension of human being in its articulation. At this point, phenomenological philosophy requires a practice of engaged social and political criticism. Such criticism no longer stands above social movements to adjudicate them in terms of their universality, but engages with their organization and goals. To this extent, such phenomenological criticism is only possible if the philosopher is also a participant in social movements. The practice of philosophy, at least in our time, as an inquiring way of life, requires that the philosopher step back from the sedimented assumptions embedded in 
dominant institutions and learn to become open to the manifestation of the new in social movements. He or she must have an eye for 'the new in the new,' and beware of reducing the event of manifestation back to the already-known that institutions provide. In this way a new task for philosophy emerges: the commitment to lived experience in phenomenology must risk the articulation of 'the new-ness of the new,' as it bursts forth from the social movements of our time. This cannot be a mere intoxication with fashion, or even a prior assumption that newness is always valuable or benign, but must read the present from the viewpoint of the emergent, from attuning oneself to the infinite dimension of such newness. Transcendental history, understood as the unbuilding of institutions, is about emergence, surging toward the future, not the given-ness of the past but how the past event came to structure its future, and thus how contemporary events manifest the new. Its being is coming-to-be. The philosopher is thrown into a risk with this coming-to-be. Description and analysis cannot be severed from a commitment to what is coming-to-be. But 'what is to come' is not a 'what,' a new given, that could become in its own time completely present. It is coming-to-be itself, emergence, time as the ek-stasis of the future. ${ }^{6}$ Social movements are the finite manifestation of the infinite open-ness of human experience to the to-come, to the infinity of human possibility that manifests itself transversally to the linearity of historical time, manifested within that linear time as the impossibility of no newness, of an in principle open-ness to which the phenomenologist must give witness.

\section{Authentic Sociality}

The awakening to the founding of knowledge and society in experience that defines phenomenology demands a turning-away from sedimented pre-knowledges, which we have 
associated with the perplexity from which Descartes' questioning begins. In this respect, thinking and witnessing must be a first-person engagement without hope of definitive resolution. It is in this sense Socratic (see Angus, "Socrates"). However, this does not exclude a newer, better, sociality built upon or confirmed by first-person engagement. It has been noted by many critics, from Karl Löwith to Herbert Marcuse, that this misunderstanding confounds the account of authenticity (Eigenlichkeit) in Being and Time: authenticity as the withdrawal into oneself demanded by the phenomenological reduction is confused with an essential estrangement from the 'we' upon which social life depends. The 'we' is thus termed a 'they' by Heidegger and, in one fell terminological swoop, the possibility of an authentic sociality is cut off (see Being and Time, pt. 1, div. 1, sec. IV). After Heidegger, and in solidarity with the new social movements, a key responsibility of phenomenology is to define and pursue authentic sociality.

Husserl's phenomenology in its final phase is oriented teleologically to a universal critique of life-forms, institutions, and a justification of the striving for knowledge. Ludwig Landgrebe has defined its effect on the philosopher through a "principle of individuation" in which anonymous life, the 'they' in Heidegger's terminology, is rendered thematic and conscious through reflection ("Problem of the Beginning" 51-2). The philosophical goal of self-knowledge, when radicalized by phenomenology, has both personal and collective dimensions. Phenomenological enlightenment consists in the rendering-explicit of the lifeforms, and subjecting them to individual and collective self-responsibility, which humans live through predominantly in the sedimented, non-original forms of tradition. Authentic sociality is the form of sociality founded upon the principle of individuation whereby reflecting individuals assume responsibility for their individual and collective actions. 
There are two aspects of authentic sociality. One depends upon distinguishing the anonymity of collective life evident in the 'they,' from a conscious sociality based upon selfresponsible individuals. This possibility, while cut off by Heidegger's collapsing of sociality with the 'they,' can be recovered by returning to the principle of individuation in Husserl's phenomenology. While phenomenological making-evident requires reflection and is thus individuating, we have already seen that social movements play the role of making-evident in the social domain. The individuation characteristic of phenomenology in the activity of philosophizing is thus matched by what we might tentatively call a 'social individuation' that occurs through social movements. New identities such as 'feminist' and 'environmentalist' are individuations made possible by engagement in social movements such that an authentic social identity is constituted.

The second aspect of authentic sociality can be derived from the description of authenticity in Heidegger. Authentic existence is the actualization of one's "ownmost possibility" in being-toward-death (Being and Time par. 53). Heidegger adumbrates the several aspects of being-toward-death in the phrase "the ownmost nonrelational possibility not-to-be-bypassed is indefinite with regard to its certainty" (245). The non-relationality of authenticity refers to its claim as being solely upon the individual in Heidegger's view. Authentic sociality thus requires that one recognize the not-to-be-bypassed possibility of the indefinite certainty of the death of the social existence one inhabits. The ownmost character of this sociality, its authenticity, derives from the certain death in an indefinite future of that which is one's own in this sociality. Whereas in authentic individual being-toward-death, Dasein "discloses itself to itself with regard to its most extreme possibility" (242), in authentic social being-toward-death, a social identity discloses itself to itself with regard to 
its most extreme possibility. Authentic sociality thus discloses itself to itself in the fate of the social form to which one authentically cleaves. Recalling what has been said about social movements as the anticipatory coming-to-be in a social form, the to-come of a social form is disclosed as its possibility through the authentic cleaving to what is manifested in a social movement.

Here it is possible to make a distinction between fate and destiny that is not possible for Heidegger, a distinction which relies upon and extends the principle of individuation that drives Husserl's phenomenology. In Being and Time fate is described through being-fordeath as an individual fate. "Only being free for death gives Da-sein its absolute goal and pushes existence into its finitude" (351). Authentic existence seizes finitude in freedom and thus realizes its fate. Destiny is distinguished from fate only by its collective nature. "Destiny is not composed of individual fates, nor can being-with-one-another be conceived of as the mutual occurrence of several subjects. ... In communication and in battle the power of destiny first becomes free" (352). Fate is the finitude of individual being-toward-death, whereas destiny is the collective fate, as it were. But not exactly. Since there is no possibility of authentic being-with in Being and Time, because authenticity is described and defined precisely through the withdrawal from sociality understood as always and everywhere the 'they,' destiny is denied the authenticity that is ascribed to fate. And, of course, there is correlatively absolutely no account of the process through which the individual authentic existence identifies itself with a collective existence. Thus, the Husserlian task of connection of the principle of individuation to a new form of self-responsible collective existence is cut off at the root. 
It is noteworthy that after Heidegger's turning from the analytic of Dasein to the thinking of Being, this language shifts because the question of individuation through beingtoward-death is left behind altogether. The distinction between destiny and fate is thus made in another way, both of which refer to the collectivity. In "The Question Concerning Technology," the "destining of revealing" is described precisely in distinction from fate, which is defined as "the inevitableness of an unchanging course" (25). Fate drops out as a concept in Heidegger's thinking and becomes simply a foil against which the concept of destiny is clarified to mean "that sending-that-gathers which first starts man upon a way of revealing, destining" (24; see also "Turning" 37-8; "Humanism" 241). Thus is elided the whole question of when, why and how an individual identifies him or herself with a community, the authentic essence of this identification, and the authentic futurity of the community which lasts beyond the death of the individual.

The distinction between fate and destiny can be made to clarify authentic sociality. Fate should be understood as passive living-within established institutions in a manner that mimics the "uncommunicating gods or the impersonal forces of nature" that phenomenology undoes through the principle of individuation. Fate is crafted into destiny when one places "intellectual and political efforts in the reflected light of their honourable origins and pressing tasks" (Angus, Border 6, 7). Human action within a collectivity builds upon and yet transforms the legacy of the past. Undertaking this task, with its risk and uncertainty, with fidelity to the past and hope for the future, is the acceptance of destiny, of what we are made and yet we make, of the never-available zero-point of human striving. I have in mind, for example, the way in which English Canada has been formed by the 'particularity' of the attempt to build a distinct English-speaking society in North America and in which this 
defence of particularity may become relevant to a world struggling against the false universality of empire (see Angus: "Empire"; "Le paradoxe"; "The Paradox"). In this sense there is a kind of individuation pertinent to collectivities. Turning fate into destiny is the project of authentic sociality. It is a localized and finite freedom, which is thus inseparable from tragedy.

\section{Negation as Infinity}

The concept of authentic sociality undergirds critiques of capitalist and bureaucratic rationality and the attempt to turn necessary human labour in the direction of concrete freedom, but it must abandon the assumption that such critiques are in principle capable of complete realization within history. While it is true enough that "a map of the world that does not include utopia is not worth even glancing at," as Oscar Wilde said (16), it is also true that the assumption of an immanent utopia has derailed genuine advances in human emancipation due to the limitation of human imagination - all utopias are dryer than life. The difference between a utopia immanent within history, which contains the error of an immanentization of human freedom that must always remain concrete and local, and an infinite dimension of critique must be maintained. This difference depends on the understanding of negation as the affirmation of time that sustains critical practice.

When phenomenology has been connected to social critique it has often been done through an appropriation of Marxism within phenomenology. The relation of philosophy to social critique within the tradition of Hegelian Marxism centres on the concept of determinate negation (see Angus, "Praise of Fire"). Critical negations, both theoretical and practical, of the dominant order are understood as contributing to the downfall of that order 
and its replacement by something better. Negation is thus the motor of both critique and historical progress. The inseparability of critique and progress here is established by the alienation story: unmediated totality is broken into isolated parts and then re-combined into a new differentiated totality. Negation of the isolated parts as isolated is thus a step toward their recombination and healing. This Hegelian theoretical model, which is claimed to be the actual movement of history, enters Marxism through the notion that capitalist society contains its own negation, an incipient reversal within the degraded state that foretells a revolutionary overcoming. Any conception of philosophy that ties it essentially to social critique must understand this tie essentially through the affinity between philosophical negation and social negation. It is this centrality of negation that phenomenology has often sought in Marxism to guarantee its social relevance.

The problem, however, is that the often-sought synthesis of phenomenology and Marxism remained elusive precisely because of the difference between the concepts of negation in Hegelian Marxism and phenomenology (see Angus, "Walking on Two Legs"). In phenomenology, once presence as self-giving intuition has been superceded by presencing, or coming-into-presence, what is called 'negation' in Hegelian Marxism is understood in terms of the relation between unconcealment and concealment. As Heidegger illuminates in his conception of phenomenology, unconcealment, or the revealing in the manifestation of Being, brings forth a truth of Being. In the same unconcealment, something withdraws and remains concealed. Concealment, in withdrawing, is nothing. In this sense, nothingness is the origin of critique. The difference is that the Hegelian Marxist concept of negation turns toward a new, higher positivity, whereas Heideggerian unconcealment simply withdraws. It remains without manifestation within this dispensation, or epoch, of the truth 
of Being. Thus, there is no incipient reversal within the dispensation and the relation to social critique might appear to be cut off. However, the notion that a phenomenological account of the manifestation of Being cannot sustain a concept of social critique is a hasty judgment often made by those for whom a Hegelian model of negation is the only possibility. Let me now try to outline a phenomenological account of negation understood as withdrawal that will sustain an effective practice of social critique.

From a phenomenological point of view the key element of the Hegelian account of negation is the evidentially ungrounded assumption that it produces a new positivity through the determinateness of negation. We might call this an 'immanentization' of negation. It is this immanentization that situates negation on the same plane as that which is negated. In turn, it is because the original positive and its negation are symmetrical that the negation produces a new positivity, which is again on the same plane. A phenomenological account of negation as withdrawal will have to drop this ungrounded assumption and accept the fact that what withdraws in unknown in its essence and effect precisely because it withdraws.

Social movements uncover what has withdrawn from the epoch. They practically negate the current régime and reveal the promise of a new dispensation. They work at, and reveal, the limits of the current dispensation. Two things must be said emphatically here: One, a new dispensation, should it arrive, will also contain a withdrawal at the very heart of what it is, indeed, of what is. Two, the new dispensation which social movements reveal through the limits of the current dispensation cannot be put on the same plane with the current one. That is to say, there can be no simple progress, indeed no thorough, complete or total through-line at all between dispensations. Rejecting an ungrounded immanentization uncovers this ineluctability. 
Each social movement reveals a limit of the dispensation. Within it glimmers an occluded infinite dimension of human being. ${ }^{7}$ In the glimmering of social movements we experience an infinity of human possibility open to human experience: a plurality of infinities, so to speak, in many dimensions or planes. We confront here the deeply, wonderfully, and terrifyingly undetermined nature of human being. Each of these infinities judges us for that which we have failed to actualize. ${ }^{8}$ They negate every instance of injustice in light of the infinite possibility of complete actualization, adequate evidence. When I stand before this terror, this wonder, I am judged for the smallness of my part. The whole of this wonder and terror cannot be actualized, be made political. There is no régime of the whole of human possibility and of settled justice. Still, it is the face of this multi-dimensional plurality which links phenomenology necessarily to social critique.

Social critique is thus plural, and relentless, and as such goes beyond that which could be contained in any politics. On what and where to insist, where and on what to bend: these are judgments which none of us can avoid. Each of us becomes who he or she is through such judgments, through taking stands and drawing lines. Here there is total selfresponsibility but there cannot be total actualization. We cannot be, or enact, everything that we can glimpse. Such is the finitude of human being, as it is defined through the infinites to which it opens out. This means that evil cannot be eliminated within history, as Hegel's theodicy expects, but is inherent in the finitude of humanity.

\section{Conclusion}

The thinking for oneself demanded by Descartes, and operative throughout the history of philosophy, produces a continuous radicalization that can be called phenomenological 
enlightenment. Bringing to evidence demands confronting the opening from which beings come into presence. An opening founds an epoch which is unbuilt in the critique of institutions. The unbuilding of phenomenological critique is the point of its solidarity with social movements that push to the limit the unconcealed of an epoch. Coming into presence thus engenders its own nothingness, or negation in Hegelian terminology. Without an immanent negation such as the Hegelian metaphysics promises, each nothing spins outward to an infinite distance. This nothing of the here-now is the very possibility and necessity of critique. Critique is the epochal function of philosophy.

\section{Notes}

${ }^{1}$ Specifically, I will seek to show that the social and political criticism that I have elsewhere elaborated is based upon phenomenological philosophy.

${ }^{2}$ This is the realm which Karl Marx referred to as 'social relations' and 'social intercourse,' though these terms do not seem to adequately capture the 'solidity,' or 'materiality,' of institutions.

${ }^{3}$ This would imply a correlative inquiry to be named 'transcendental spatiality.'

${ }^{4}$ The term Abbau arose in connection with Husserl's investigations into 'Genetic Logic' in about 1921 and surfaced afterward whenever it was an issue of genetic constitution. The genetic constitution of the predicative logical judgments from pre-predicative experience was the major theme of genetic logic. This concern arises in the specific case of the crisis of European sciences because the thesis of the 'loss of meaning' entails a certain dislocation, or disruption, of the relation of formation of pre-predicative experience by predicative judgements or, to speak more generally, of the formation of experience by formal knowledgesystems. The zigzag pattern of presentation that an investigation into the institution of modern science demands is based on a form of inquiry in which the instituted object - in this case Galilean science - is dismantled into its components and the constitution of its originary form is clarified. Such a dismantling, Husserl notes, has a double aspect of 'going back,' or regressive inquiry (Rückgang).

5 A genetic inquiry into a historical institution thus requires: 1. an instituted object (Urstiftung) such as Galilean science; 2. a tracing back (Rückgang) of the sedimentations of 
instituted meaning whereby it has gained its historical 'weight' or 'solidity,' to their prepredicative origin; 3. a dismantling (Abbau) of this pre-predicative experience itself; and 4. a zigzag pattern of presentation that goes back and forth between the originary institution and the contemporary situation.

${ }^{6}$ For this reason Jacques Derrida has described this to-come, futurity, of experience as "the messianic appeal [which] belongs properly to a universal structure, to that irreducible movement of the historical opening to the future" (167).

7 One cannot say whether this occluded dimension could ever be actualized, even in approximation, in an actually-given human society. One may certainly suspect that all the dimensions that glimmer could not be all together actualized. Let us postpone actualization, or at least its possibility, which is the being of politics as such, for a moment in order to stay with what glimmers.

${ }^{8}$ It is in this way that I would attempt to recover the significance of revelation for philosophy: we are judged by the infinity which withdraws. In this sense, the infinity not only spins outwards but also returns. This return has perhaps been captured better by the tradition stemming from Jerusalem than that of Athens. I argue, against George Grant, that an ontotheological concept of God is not required by philosophy, but I accept, with Hermann Cohen, that a concept of the infinite bears an important relation to the Hebrew revelation (see Angus, "Athens and Jerusalem").

\section{Works Cited}

Angus, Ian. A Border Within: National Identity, Cultural Plurality and Wilderness. Montreal and Kingston: McGill-Queen's Press, 1997.

—. (Dis)figurations: Discourse/Critique/Ethics. London: Verso, 2000.

-. Primal Scenes of Communication: Communication, Consumerism, Social Movements. Albany: State University of New York Press, 2000.

—. Emergent Publics: An Essay on Social Movements and Democracy. Winnipeg: Arbeiter Ring, 2001.

—. "Le paradoxe de l'identité culturelle au Canada anglais." Trans. Jean-Phillipe Warren and Michel Lavoie. Les Cahiers de recherche sociologique, 39 (2003).

—. "The Paradox of Cultural Identity in English Canada." Topia: Canadian Journal of Cultural Studies, no. 10 (Fall 2003). 
—. "Empire, Borders, Place: A Critique of Hardt and Negri's Concept of Empire." Theory and Event, 7, no. 3 (2004).

—. "In Praise of Fire: Responsibility, Manifestation, Polemos, Circumspection." The New Yearbook for Phenomenology and Phenomenological Philosophy, 4 (2004).

—. "Athens and Jerusalem? A Critique of the Relation Between Philosophy and Religion in George Grant's Thought." Journal of Canadian Studies, 39, no.2 (2005).

—. "Media, Expression and a New Politics: Eight Theses." Media and Cultural Politics, 1, no. 1 (2005).

—. "Socrates and the Critique of Metaphysics." The European Legacy, 10, no. 4 (2005).

—. "Walking on Two Legs: On The Very Possibility of a Heideggerian Marxism." Rev. of Heidegger and Marcuse: The Catastrophe and Redemption of History, by Andrew Feenberg. Human Studies (Fall 2005).

—. "Hermann Cohen's Concept of the Infinite Judgment." Canadian Society for Continental Philosophy, Annual Meeting, York University (2006).

Derrida, Jacques. Specters of Marx. Tr. Peggy Kamuf. New York: Routledge, 1994.

Heidegger, Martin. "Letter on Humanism." Basic Writings. Ed. David Farrell Krell. New York: Harper and Row, 1977.

—. "The Question Concerning Technology." The Question Concerning Technology and Other Essays. Tr. William Lovitt. New York: Harper and Row, 1977.

—. "The Turning." The Question Concerning Technology and Other Essays. Tr. William Lovitt. New York: Harper and Row, 1977.

—. Being and Time. Tr. Joan Stambaugh. Albany: State University of New York Press, 1996.

Husserl, Edmund. The Crisis of European Sciences and Transcendental Phenomenology. Tr. David Carr. Evanston: Northwestern University Press, 1970.

—. Experience and Judgment. Tr. James S. Churchill and Karl Ameriks. Evanston: Northwestern University Press, 1973.

-. Ideas Pertaining to a Pure Phenomenology and to Phenomenological Philosophy, First Book. Tr. F. Kersten. The Hague: Martinus Nijhoff, 1982. 
Landgrebe, Ludwig. "Editor's Foreword to the 1948 Edition." Experience and Judgment. By Edmund Husserl. Tr. James S. Churchill and Karl Ameriks. Evanston: Northwestern University Press, 1973.

—. "The Problem of the Beginning of Philosophy in Husserl's Phenomenology." LifeWorld and Consciousness: Essays for Aron Gurwitsch. Tr. José Huertas-Jourda. Ed. Lester E. Embree. Evanston: Northwestern University Press, 1972.

—. The Phenomenology of Edmund Husserl. Ed. Donn Welton. Ithaca: Cornell University Press, 1981.

Wilde, Oscar. The Soul of Man in The Soul of Man and Prison Writings. Oxford: Oxford University Press, 1990. 